\title{
Changes in alcohol consumption in pregnant Australian women between 2007 and 2011
}

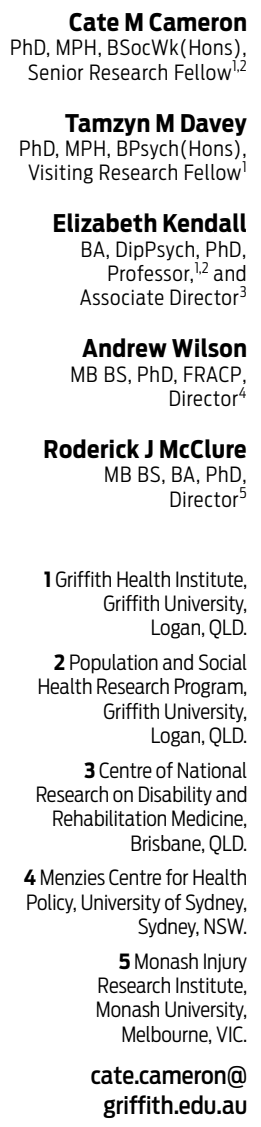

MJA 2013; 199: 355-357 doi: 10.5694/mjal2.11723 lcohol consumption during pregnancy may contribute to birth defects, growth and developmental abnormalities, and fetal mortality. ${ }^{1-3}$ In 2009, the National Health and Medical Research Council (NHMRC) revised its guidelines, recommending that the safest option for pregnant women, and women planning a pregnancy, was to not consume alcohol at all. ${ }^{2}$

Although Australia conducts routine National Drug Strategy Household Surveys, changes made in 2010 to the survey questions about alcohol use during pregnancy - to incorporate drinking before and after knowledge of pregnancy - preclude direct comparisons over time. ${ }^{4}$ Thus, we aimed to describe the prevalence and distribution of alcohol use during pregnancy in an Australian population over the 5-year period 2007 to 2011.

\section{Methods}

\section{Study design and data sources}

We undertook a cross-sectional repeated sample, trend analysis of alcohol consumption patterns during pregnancy. Data were obtained from baseline surveys of pregnant women participating in the Griffith Study of Population Health: Environments for Healthy Living (EFHL study) from 2007 to 2011. This longitudinal birth cohort study annually recruits participants from public maternity hospitals in the Logan-Beaudesert, Gold Coast and Tweed health districts in southeast Queensland and north-east New South Wales. ${ }^{5}$

Participants completed a baseline, self-administered questionnaire, which included items from the 2004 National Drug Strategy Household Survey ${ }^{6}$ relating to alcohol consumption, modified for pregnancy. Images and information about different alcohol types and what constitutes a standard drink were provided. ${ }^{6}$ Participants were asked about alcohol consumption (any level) and high-risk alcohol consumption (five or more standard drinks on any one occasion) at early,

\begin{abstract}
Abstrac
Objective: To describe the prevalence and distribution of alcohol consumption during pregnancy in an Australian population over a 5-year period.

Design, setting and participants: Cross-sectional repeated sample, trend analysis of aggregated and stratified alcohol consumption patterns during pregnancy. Pregnant women were enrolled from 2007 to 2011 in the Griffith Study of Population Health: Environments for Healthy Living, a birth cohort study being conducted in south-east Queensland and north-east New South Wales.
\end{abstract}

Main outcome measures: Sociodemographic and alcohol consumption data were self-reported at enrolment. Alcohol measures included alcohol consumption (any level) and high-risk alcohol consumption, both during pregnancy (at any stage) and after the first trimester of pregnancy.

Results: Of 2731 pregnant women for whom alcohol consumption data were available, a decrease in alcohol consumption was observed over the study period; $52.8 \%$ reported alcohol use in 2007 compared with 34.8\% in $2011(P<0.001)$. The proportion of women who drank alcohol after the first trimester of pregnancy declined from $42.2 \%$ in 2007 to $25.8 \%$ in 2011 . However, high-risk drinking patterns - at all or after the first trimester - did not change over the 5 years $(P=0.12)$. Lowlevel alcohol consumption was associated with older women $(P<0.001)$, more highly educated women $(P=0.01)$, and women from higher-income households $(P<0.001)$. In contrast, high-risk consumption after the first trimester was associated with lower levels of education $(P=0.011)$ and single-parent status $(P=0.001)$.

Conclusions: This study showed a steady and statistically significant decline in the proportion of women who reported drinking alcohol during pregnancy from 2007 to 2011. To further reduce these levels, we need broad public health messages for the general population and localised strategies for high-risk subpopulations.

Trial registration: Australian New Zealand Clinical Trials Registry ACTRN12610000931077.

mid and late pregnancy $(0-13,14-26$ and 27-42 weeks, respectively). They were also asked about low-level alcohol use, which was defined as consuming between half a standard drink and two standard drinks on any occasion. Data on maternal age, education, marital status, income, smoking and recreational drug use were also collected. ${ }^{5}$

\section{Data management and analysis}

Data cleaning and descriptive analyses were undertaken using SAS 9.2 software (SAS Institute Inc). Pearson $\chi^{2}$ and Fisher exact tests were performed to describe aggregated and stratified alcohol consumption patterns over the study period. Significance was set at a level of 5\%. Small cell sizes prevented regression analyses.

\section{Ethics approval}

The EFHL study was approved by the human research ethics committees of Griffith University, Metro South Health Service District, Gold Coast Health Service District and North Coast Area Health Service.

\section{Results}

From 2007 to 2011, 2743 pregnant women were enrolled in the EFHL study (age range, 16-52 years). Alcohol consumption data were available for 2731 of them, and 1206 (44.2\%) reported drinking alcohol at some time during pregnancy. In total, 917 women $(33.7 \%)$ reported consuming alcohol after the first trimester of pregnancy, when they would have been aware of their pregnancy, and 68 women $(2.5 \%)$ reported drinking at high-risk levels after the first trimester (Box 1).

\section{Sociodemographic patterns of alcohol use}

The mean age of women who reported drinking alcohol after the first trimester of pregnancy was 30.5 years, which was significantly older than the women who reported no alcohol consumption or consumption only in the first trimester (28.6 years) $(P<0.001)$. In contrast, the mean age of women drinking at high-risk levels was younger than that of women who 
1 Alcohol consumption during pregnancy, by maternal and household sociodemographic variables, level of consumption and stage of pregnancy, 2007-2011

\begin{tabular}{|c|c|c|c|c|c|c|c|c|c|}
\hline & \multirow[b]{3}{*}{ No. } & \multicolumn{4}{|c|}{ Any stage of pregnancy } & \multicolumn{4}{|c|}{ After first trimester } \\
\hline & & \multicolumn{2}{|c|}{$\begin{array}{c}\text { Alcohol } \\
\text { consumption }\end{array}$} & \multicolumn{2}{|c|}{$\begin{array}{c}\text { High-risk alcohol } \\
\text { consumption* }\end{array}$} & \multicolumn{2}{|c|}{$\begin{array}{c}\text { Alcohol } \\
\text { consumption }\end{array}$} & \multicolumn{2}{|c|}{$\begin{array}{c}\text { High-risk alcohol } \\
\text { consumption* }\end{array}$} \\
\hline & & No. $(\%)^{\dagger}$ & $P^{\ddagger}$ & No. $(\%)^{\dagger}$ & $P^{\ddagger}$ & No. $(\%)^{\dagger}$ & $P^{\ddagger}$ & No. $(\%)^{\dagger}$ & $P^{\ddagger}$ \\
\hline Total & 2731 & $1206(44.2 \%)$ & $<0.001$ & $240(8.9 \%)$ & $<0.001$ & $917(33.7 \%)$ & $<0.001$ & $68(2.5 \%)$ & $<0.001$ \\
\hline \multicolumn{10}{|l|}{ Maternal age } \\
\hline$<25$ years & 651 & $237(36.4 \%)$ & $<0.001$ & $64(9.9 \%)$ & 0.550 & $150(23.2 \%)$ & $<0.001$ & $20(3.1 \%)$ & 0.365 \\
\hline $25-29$ years & 798 & $318(39.8 \%)$ & & $62(7.9 \%)$ & & $240(30.2 \%)$ & & $22(2.8 \%)$ & \\
\hline 30-34 years & 703 & $363(51.6 \%)$ & & $65(9.3 \%)$ & & $289(41.2 \%)$ & & $16(2.3 \%)$ & \\
\hline $35+$ years & 566 & $283(50.0 \%)$ & & $48(8.6 \%)$ & & $234(41.5 \%)$ & & $9(1.6 \%)$ & \\
\hline Missing & 13 & 5 & & 1 & & 4 & & 1 & \\
\hline \multicolumn{10}{|l|}{ Maternal education } \\
\hline Did not complete school & 560 & $237(42.3 \%)$ & 0.073 & $62(11.2 \%)$ & 0.034 & $165(29.6 \%)$ & 0.010 & $22(4.0 \%)$ & 0.011 \\
\hline Completed high school & 839 & $349(41.6 \%)$ & & $71(8.6 \%)$ & & $267(32.0 \%)$ & & $18(2.2 \%)$ & \\
\hline Trade or apprenticeship & 786 & 374 (47.6\%) & & $74(9.5 \%)$ & & 276 (35.2\%) & & $23(3.0 \%)$ & \\
\hline University degree & 533 & $241(45.2 \%)$ & & $33(6.2 \%)$ & & $204(38.4 \%)$ & & $5(0.9 \%)$ & \\
\hline Missing & 13 & 5 & & 0 & & 5 & & 0 & \\
\hline \multicolumn{10}{|l|}{ Country of birth } \\
\hline Australia & 1906 & $876(46.0 \%)$ & 0.005 & $167(8.8 \%)$ & 0.940 & $665(35.0 \%)$ & 0.032 & $47(2.5 \%)$ & 0.902 \\
\hline Other & 823 & $330(40.1 \%)$ & & $73(8.9 \%)$ & & $252(30.8 \%)$ & & $21(2.6 \%)$ & \\
\hline Missing & 2 & 0 & & 0 & & 0 & & 0 & \\
\hline \multicolumn{10}{|l|}{ Marital status } \\
\hline Single-parent family & 364 & $168(46.2 \%)$ & 0.429 & $51(14.3 \%)$ & $<0.001$ & $113(31.3 \%)$ & 0.290 & $18(5.0 \%)$ & 0.001 \\
\hline Two-parent family & 2351 & $1033(43.9 \%)$ & & $186(8.0 \%)$ & & $800(34.1 \%)$ & & $50(2.1 \%)$ & \\
\hline Missing & 16 & 5 & & 3 & & 4 & & 0 & \\
\hline \multicolumn{10}{|l|}{ Annual household income } \\
\hline Lowest quintile & 448 & $176(39.3 \%)$ & $<0.001$ & $51(11.4 \%)$ & 0.054 & $119(26.6 \%)$ & $<0.001$ & $18(4.0 \%)$ & 0.072 \\
\hline Second quintile & 451 & $176(39.0 \%)$ & & 31 (6.9\%) & & 134 (30.0\%) & & $6(1.4 \%)$ & \\
\hline Third quintile & 448 & $193(43.1 \%)$ & & $31(7.0 \%)$ & & $154(34.5 \%)$ & & $11(2.5 \%)$ & \\
\hline Fourth quintile & 451 & $207(45.9 \%)$ & & $39(8.7 \%)$ & & $158(35.1 \%)$ & & $7(1.6 \%)$ & \\
\hline Highest quintile & 449 & $260(57.9 \%)$ & & $48(10.7 \%)$ & & $215(47.9 \%)$ & & $11(2.5 \%)$ & \\
\hline Missing & 484 & 194 & & 40 & & 137 & & 15 & \\
\hline \multicolumn{10}{|l|}{ Cigarette smoking } \\
\hline Smoked & 681 & $358(52.6 \%)$ & $<0.001$ & $126(18.6 \%)$ & $<0.001$ & 264 (38.9\%) & 0.001 & $44(6.5 \%)$ & $<0.001$ \\
\hline Did not smoke & 2044 & $844(41.3 \%)$ & & 114 (5.6\%) & & $651(32.0 \%)$ & & $24(1.2 \%)$ & \\
\hline Missing & 6 & 4 & & 0 & & 2 & & 0 & \\
\hline \multicolumn{10}{|l|}{ Recreational drug use } \\
\hline Used drugs & 149 & $102(68.5 \%)$ & $<0.001$ & $44(29.7 \%)$ & $<0.001$ & $85(57.1 \%)$ & $<0.001$ & $20(13.5 \%)$ & $<0.001$ \\
\hline Did not use drugs & 2538 & $1084(42.7 \%)$ & & $191(7.6 \%)$ & & 815 (32.2\%) & & $45(1.8 \%)$ & \\
\hline Missing & 44 & 20 & & 5 & & 17 & & 3 & \\
\hline
\end{tabular}

did not report high-risk consumption or drank only in the first trimester (27.7 years $\mathrm{v} 29.3$ years) $(P=0.03)$.

The proportion of women consuming low levels of alcohol after the first trimester significantly increased with increasing age $(P<0.001)$, increasing levels of education $(P=0.01)$ and increasing household income $(P<0.001)$. Women who smoked cigarettes and used recreational drugs during pregnancy were more likely to consume alcohol $(P<0.001$ for both) (Box 1).

High-risk drinking after the first trimester was reported by $3.1 \%$ of women younger than 25 years and $4.0 \%$ of those in the lowest household income quintile (Box 1). Also, highrisk drinking after the first trimester was associated with lower levels of education $(P=0.011)$ and single-parent status $(P=0.001)$, was 5.4 times more likely among women who smoked than among non-smokers, and was 7.5 times more likely among women who used recreational drugs than among non-drug users (Box 1).

\section{Temporal patterns of alcohol use}

From 2007 to 2011, the proportion of women who reported drinking alcohol during pregnancy significantly decreased; 251 of 475 women (52.8\%) reported alcohol use in 2007, compared with 168 of 483 (34.8\%) in 2011 $(P<0.001)$ (Box 2). The proportion of women who drank alcohol after the first trimester of pregnancy declined from 200 of 474 women $(42.2 \%)$ in 2007 to 124 of 481 (25.8\%) in 2011 (Box 2). The proportion of women who consumed alcohol during every trimester of pregnancy almost halved from 2007 (99/474; 20.9\%) to 2011 (53/481; 11.0\%). However, for those who reported high-risk consumption - at all or after the first trimester - 
there was no statistically significant change over the 5 years $(P=0.12)$.

Despite the overall decrease in alcohol consumption after the first trimester of pregnancy from 2007 to 2011, no significant decrease was found for women older than 35 years $(P=0.11)$, single parents $(P=0.07)$, those in the lowest household income quintile $(P=0.54)$, those with a trade or apprenticeship education $(P=0.28)$ or those who used recreational drugs $(P=0.13)$. Also, there was no significant change in high-risk drinking patterns after the first trimester for any sociodemographic group over the 5 years.

\section{Discussion}

This study shows a steady and statistically significant decline in the proportion of women who reported drinking alcohol during pregnancy from 2007 to 2011. The proportion of women who continued to drink alcohol after their first trimester of pregnancy also declined. It is possible that increased media emphasis on the negative effects of alcohol during pregnancy $^{7,8}$ may have increased underreporting of alcohol consumption during the study period, thus resulting in this overall decline. Although alcohol consumption in the general population also declined during the study period, ${ }^{9}$ this study showed no change in alcohol consumption after the first trimester for older women, single parents, lowincome women, women with a trade or apprenticeship education, or women who used recreational drugs. Further, the proportion of women who reported high-risk drinking (five standard drinks or more on any one occasion) did not change over the 5 -year period. This finding may have been related to the small sample size, but it is also possible that public health programs and national policies are not reaching women who are most at risk of having babies with alcohol-related birth defects.

Consistent with some other risk behaviour, $^{10-12}$ there was a socioeconomic differential in drinking patterns during pregnancy: low-level alcohol consumption after the first trimester increased with increasing age, education and income, and high-risk consumption after the first trimester was more common in single women and women who did not complete school. It is particularly concerning that women who continued high-risk drinking after the first trimester were also much more likely to smoke cigarettes or use recreational drugs, which are also associated with adverse pregnancy outcomes. ${ }^{13,14}$

Given that the sociodemographic composition of the cohorts did not change across the 5 years of recruitment, $^{15}$ the findings are not likely to be a result of random variation in participant sampling or demographic shifts in the study region. Nevertheless, it is possible that the study was biased slightly towards women with lower levels of alcohol consumption, because inclusion in the study was dependent on reaching the third trimester of pregnancy. ${ }^{2}$ Women who had experienced early fetal loss, which may have been associated with high levels of alcohol consumption, were not included.

The most recent Australian guidelines advocate abstinence from alcohol during pregnancy. Although our results suggest that national alcohol and pregnancy policies and public health programs may have had some effect in reducing population-level alcohol use by pregnant women, these may not affect the behaviour of specific at-risk groups. Thus, it is necessary to provide broad public health messages for the general population and more localised strategies for high-risk subpopulations.

Acknowledgements: This research is part of the EFHL study, which receives core funding from Griffith University and is also funded by an Australian Research Council Discovery Project grant (DPI10105423). The EFHL study was conceived by Roderick McClure, Cate Cameron, Judy Searle and Ronan Lyons. We gratefully acknowledge the chief investigators, project, administrative and research staff, and hospital antenatal and birth suite midwives of the participating hospitals for helping to conduct the study. Cate Cameron was supported by a Public Health Fellowship (ID 428254) from the NHMRC.

\section{Competing interests: No relevant disclosures.}

Received 25 Nov 2012, accepted 30 May 2013.

1 Andersen AM, Andersen PK, Olsen J, et al. Moderate alcohol intake during pregnancy and risk of fetal death. Int JEpidemiol 2012; 41: 405-413.

2 National Health and Medical Research Council. Australian guidelines to reduce health risks from drinking alcohol. Canberra: NHMRC, 2009. http:// www.nhmrc. gov.au/guidelines/publications/ds10 (accessed Jun 2013).

3 Burd L, Klug MG, Li Q, et al. Diagnosis of fetal alcohol spectrum disorders: a validity study of the fetal alcohol syndrome checklist. Alcohol 2010; 44: 605-614.

4 CallinanS, Room R. Alcohol consumption during pregnancy: results from the 2010 National Drug Strategy Household Survey. Canberra: Foundation for Alcohol Research and Education, 2012. http://www.
2 Proportion of women who consumed alcohol during pregnancy, by level of consumption and stage of pregnancy, 2007-2011

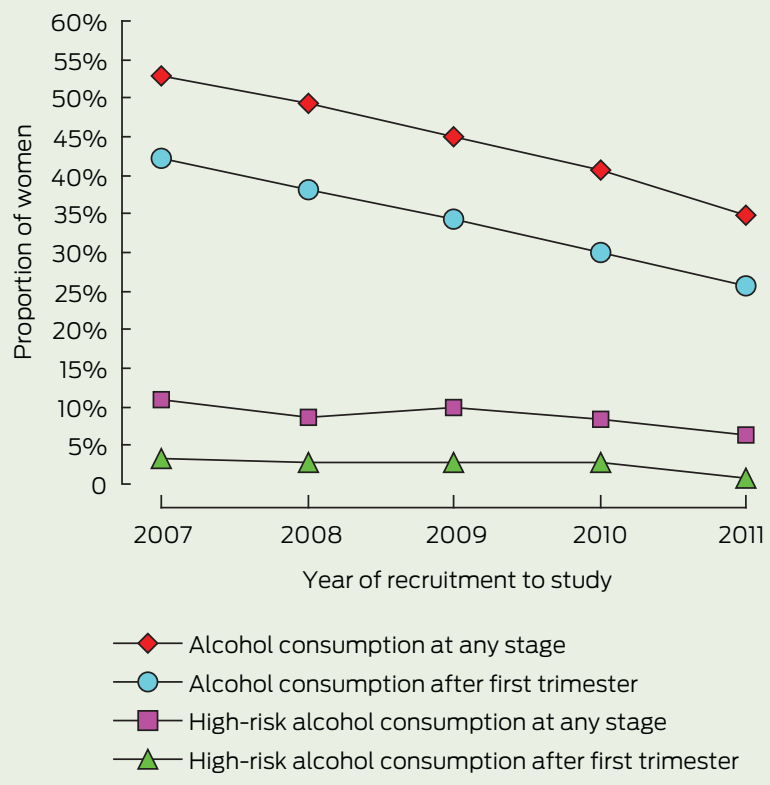

health infonet.ecu.edu.au/key-resources/bibliography/ ?lid=23341 (accessed Jun 2013).

5 Cameron CM, Scuffham PA, Spinks A, et al. Environments for Healthy Living (EFHL) Griffith birth cohort study: background and methods. Matern Child Health J 2012; 16: 1896-1905.

6 Australian Institute of Health and Welfare. 2004 National Drug Strategy Household Survey: detailed findings. Canberra: AlHW, 2005. (AlHW Cat. No. PHE 66; Drug Statistics Series No. 16.) http://www.aihw.gov. au/publication-detail/?id=6442467781 (accessed Aug 2013).

7 Centre for Health Promotion. Pregnancy and alcohol don't mix. Adelaide: Centre for Health Promotion, 2007.http://www.healthinfonet.ecu.edu.au/keyresources/promotion-resources?lid=19111 (accessed Aug 2013).

8 Queensland Health. Young women and alcohol campaign. Make up your own mind about drinking. http://www.health.qld.gov.au/atod/prevention/ young_women.asp (accessed Mar 2013).

9 Australian Institute of Health and Welfare. 2010 National Drug Strategy Household Survey report. Canberra: AlHW, 2011. (AlHW Cat. No. PHE 145; Drug Statistics Series No. 25.) http://www.aihw.gov.au/ publication-detail/?id=32212254712 (accessed Aug 2013).

10 Bergman MM, Scott J. Young adolescents' wellbeing andhealth-riskbehaviours: gender and socio-economic differences. J Adolesc 2001; 24: 183-197.

11 Barreto SM, Figueiredo RC. Chronic diseases, selfperceived health status and health risk behaviors: gender differences. Rev Saude Publica 2009; 43 Suppl 2:38-47.

12 Tuinstra J, Groothoff JW, van den Heuvel WJ, Post D. Socio-economic differences in health risk behavior in adolescence: do they exist? Soc Sci Med 1998; 47: 67-74.

13 HackshawA, RodeckC, Boniface S. Maternal smoking in pregnancy and birth defects: a systematic review based on 173687 malformed cases and 11.7 million controls. Hum Reprod Update 2011; 17: 589-604.

14 Wong S, Ordean A, Kahan M; Society of Obstetricians and Gynecologists of Canada. SOGC clinical practice guidelines: substance use in pregnancy: no. 256, April 2011. Int J Gynaecol Obstet 2011; 114: 190-202

15 Cameron CM, Scuffham PA, Shibl R, et al. Environments For Healthy Living (EFHL) Griffith birth cohort study: characteristics of sample and profile of antenatal exposures. BMC Public Health 2012; 12: 1080. 